\title{
Evaluation of the criticality of thermal bridges
}

\author{
Simo Ilomets ${ }^{1} \cdot$ Targo Kalamees ${ }^{1}$
}

Received: 27 May 2016/Accepted: 14 September 2016/Published online: 31 October 2016

(C) Springer International Publishing Switzerland 2016

\begin{abstract}
Thermal bridges can be an important reason for the renovation of old apartment buildings. This study presents a method for the critical analysis of thermal bridges. The risk of failure, i.e., surface condensation or mould growth, is evaluated by using the temperature factor $f_{\text {Rsi.load }}$ based on indoor hygrothermal loads and the temperature factor $f_{\text {Rsi.resistance }}$ from thermography measurements. The proposed method is employed for two practical applications-a case study analysis of the entire Estonian apartment building stock and a case study concerning the thermal bridges before and after the renovation of a precast concrete large-panel apartment building. The results show that critical thermal bridges caused by low surface temperature exist in all types of apartment buildings. The measured temperature factors were as low as $f_{\text {Rsi.res }}<0.65$ for several junctions in concrete buildings and for the external wall/window junctions of brick buildings. The temperature factors from indoor hygrothermal loads are as high as $f_{\text {Rsi.load }}=0.99$ for the worst dwelling unit and $f_{\text {Rsi.load }}=0.80$ at a $90 \%$ reliability level for mould growth in concrete buildings. The calculated risk for surface condensation is $45-51 \%$ and for mould growth is $45-54 \%$; this is highest in concrete buildings for both criteria. The calculated results are confirmed by visually detected mould growth, which ranges between 28 and $46 \%$ depending on the type of building. The proposed method can be used in
\end{abstract}

Simo Ilomets

simo.ilomets@ttu.ee

1 Department of Structural Design, Chair of Building Physics and Energy Efficiency, Faculty of Civil Engineering, Tallinn University of Technology, Ehitajate tee 5, 19086 Tallinn, Estonia stochastic analysis if the present need for renovation or designed renovation alternatives is under consideration.

Keywords Thermal bridge $\cdot$ Temperature factor $\cdot$ Mould growth · Probabilistic · Risk of failure · Thermography

\section{Introduction}

A thermal bridge is a part of the building envelope where the thermal transmittance is significantly larger at a local level in comparison to the surrounding area. Thermal bridges are mainly caused by geometrical or structural reasons or due to a full or partial discontinuation of the thermal insulation. Thermal bridges may lead to surface damage and hygiene problems, such as mould growth, surface condensation and the staining of surfaces. The fact that thermal bridges in a building envelope can cause considerable heat loss was detailed in the 1980s [1-3]. This factor should also be considered in the design of modern buildings $[4,5]$ because the relative significance of heat loss through thermal bridges is increased when there is a general decrease in thermal transmittance [6-9]. In short, the parameters that influence the criticality and probability of thermal bridges are presented in Fig. 1.

In the qualitative evaluation of the criticality of thermal bridges, the temperature factor on the internal surface $\left(f_{\text {Rsi }},-\right)$ [10-12] can be used. The temperature factor (also referred as the temperature ratio in research publications) on the internal surface depends on the ratio of total thermal resistance of the building envelope $R_{\mathrm{T}}\left(\mathrm{m}^{2} \mathrm{~K} / \mathrm{W}\right)$ without the internal surface resistance $R_{\mathrm{si}}\left(\mathrm{m}^{2} \mathrm{~K} / \mathrm{W}\right)$ to the total thermal resistance of the building envelope. The temperature factor can be calculated as the difference between the internal surface temperature $\left(t_{\mathrm{si}}\right.$, $\left.{ }^{\circ} \mathrm{C}\right)$ and the outdoor air temperature $\left(t_{\mathrm{e}},{ }^{\circ} \mathrm{C}\right)$ divided by the 
Fig. 1 Parameters that influence the criticality of thermal bridges

\section{Criticality of thermal bridges}

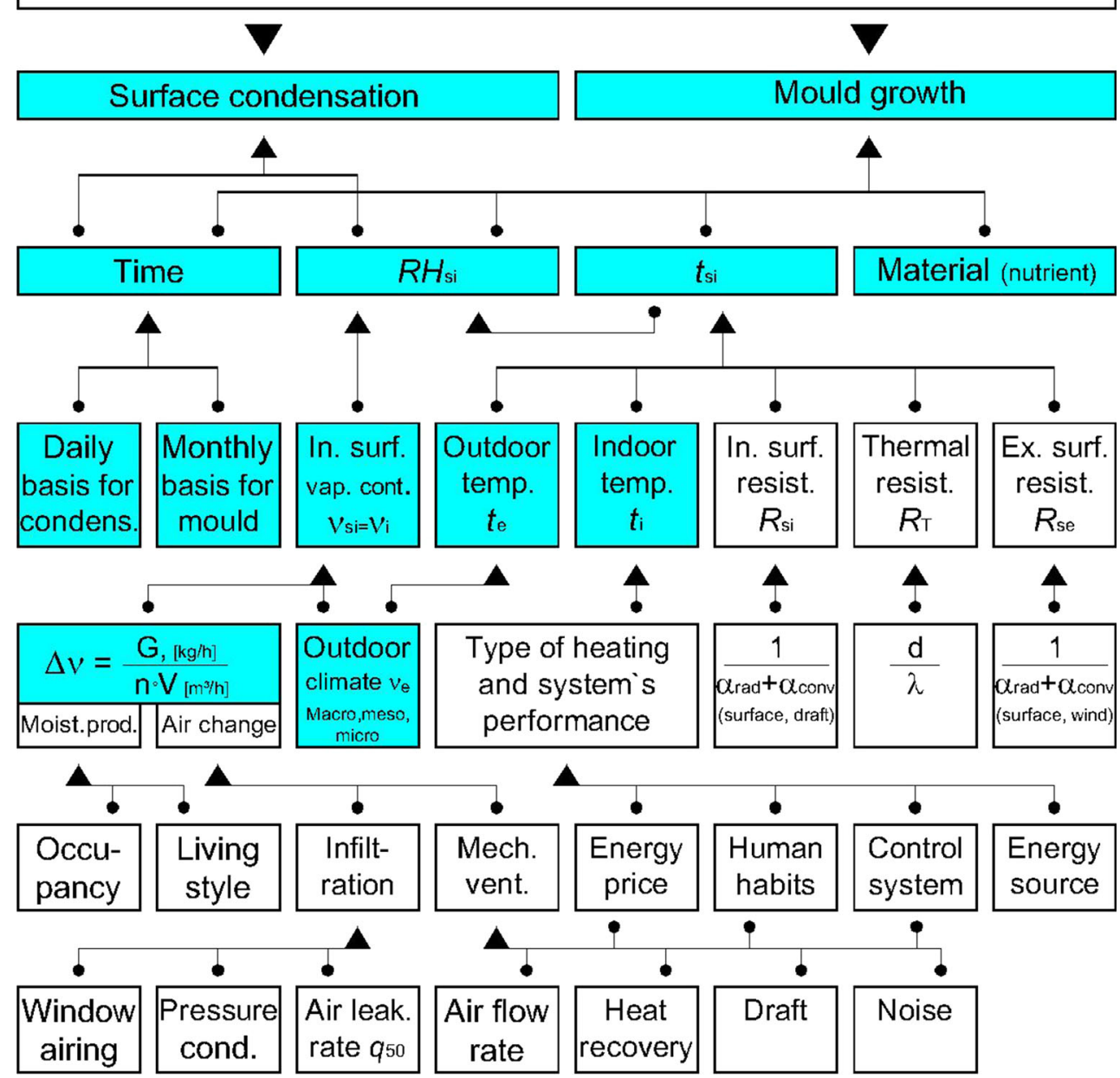

difference between the indoor air temperature $\left(t_{\mathrm{i}},{ }^{\circ} \mathrm{C}\right)$ and the outdoor air temperature, Eq. 1. The surface temperature of thermal bridges can be either calculated [12] or measured $[13,14]$.

$f_{R s i}=\frac{t_{s i}-t_{e}}{t_{i}-t_{e}}=\frac{R_{T}-R_{s i}}{R_{T}}$

The limit value of the temperature factor depends on the indoor hygrothermal loads, outdoor climate, specific junction, hygrothermal criteria and other factors, and it varies between 0.6 and 0.8 depending on the country [15-20].

Many old buildings, especially those built before the first energy crisis in the 1970s, contain serious thermal bridges [21, 22]. Many of these buildings were constructed according to standard design with similar architectural and structural typology, including typical thermal bridges. The elimination of these structural thermal bridges could be one reason for renovation.
This study presents a methodology to determine the criticality of thermal bridges based on statistical analysis of the temperature factors by using distributions of thermal bridges measured with thermography and indoor hygrothermal loads. The methodology presented could be used in the risk assessment and analysis of the need for renovation of both an individual building level and the whole building stock. It is necessary to analyse thermal bridges in order to make decisions regarding the technical solutions of building envelope renovation.

\section{Methods}

\section{Buildings studied}

Apartment buildings (blocks of flats) from different eras and typology were included in the analysis of thermal bridges. Based on external wall material, three different 
types were studied: precast concrete large-panel (hereafter: concrete) (13 buildings), brick (15 buildings) and wooden $\log$ (20 buildings).

The external walls of concrete buildings built between 1962 and 1990 are composed of two layers of reinforced concrete (50-130 $\mathrm{mm}$ inner, load-bearing layer and $50-80 \mathrm{~mm}$ outer core) with thermal insulation of $100-150 \mathrm{~mm}$ in between (fibrolite, mineral wool, phenolic foam or expanded polystyrene). Different elements are welded and casted together in situ. The thermal transmittance $U$ of solid walls varies between 0.5 and $1.0 \mathrm{~W} /$ $\left(\mathrm{m}^{2} \mathrm{~K}\right)$, and 0.7 and $1.0 \mathrm{~W} /\left(\mathrm{m}^{2} \mathrm{~K}\right)$ for roofs.

The external walls of brick buildings have an inner, load-bearing layer of $250-630 \mathrm{~mm}$ in thickness (typically calcium silicate brick), $60-120 \mathrm{~mm}$ of mineral wool thermal insulation and a $120 \mathrm{~mm}$ external layer (calcium silicate or ceramic brick). The thermal transmittance of solid walls varies between 0.5 and $1.2 \mathrm{~W} /\left(\mathrm{m}^{2} \mathrm{~K}\right)$ and 0.7 and 1.0 $\mathrm{W} /\left(\mathrm{m}^{2} \mathrm{~K}\right)$ for roofs. In general, slabs on the ground and cellar ceilings are uninsulated in these structures.

Typical wooden log dwellings from the first half of the twentieth century have 2-3 storeys. The external walls are built with a horizontal or vertical load-bearing log wall of $120-180 \mathrm{~mm}$ in thickness. The inserted ceilings are usually built of wooden beams. Cellar ceilings are also made of concrete on steel beams. The thermal transmittance of solid wooden walls varies between 0.5 and $0.9 \mathrm{~W} /\left(\mathrm{m}^{2} \mathrm{~K}\right)$. Attics and cellars are generally unheated, and the thermal transmittance of those inserted ceilings that separate the heated space is $\sim 0.5 \mathrm{~W} /\left(\mathrm{m}^{2} \mathrm{~K}\right)$.

\section{Measurements}

To determine typical thermal bridges and their distribution, measurements with a FLIR ThermaCam E320 infrared camera (thermal sensitivity of $0.1{ }^{\circ} \mathrm{C}$, measurement range from -20 to $+500{ }^{\circ} \mathrm{C}$ ) were conducted during the winter in 48 buildings. European standard EN 13187 [14] was followed when the temperature difference between the indoor and outdoor air was at least $20 \mathrm{~K}$. Up to four dwelling units (i.e., apartments) were studied in each apartment building.

The presence of mould growth on the internal surface of a thermal bridge was visually inspected using the simple tape-lift method [23] and microscopic analysis in the laboratory.

The indoor humidity loads in apartments were determined based on indoor climate measurements with small data loggers for temperature and relative humidity $(\mathrm{RH})$ (HOBO U12-013; temperature measurement range: -20 and $+70{ }^{\circ} \mathrm{C}$ with an accuracy of $\pm 0.35{ }^{\circ} \mathrm{C}$; RH measurement range: 5 and $95 \%$ with an accuracy of $\pm 2.5 \%$ in the 10-90\% RH range) at 1-h intervals over a 1-year period in the master bedroom and/or living room. The long-term outdoor climate was measured near the building or obtained from the nearest weather station.

\section{Evaluation of the probability of failure}

A lower surface temperature on a thermal bridge leads to higher RH on the surface. Two types of failure were used in this study:

- $\quad$ surface condensation: $f$ (relative humidity: (water vapour pressure, saturation vapour pressure));

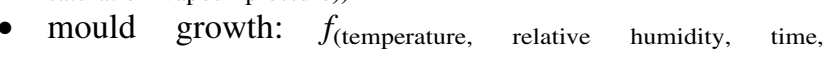
nutrient (surface material)) .

The temperature factor at the internal surface $\left(f_{\mathrm{Rsi}},-\right)$ was used to evaluate the criticality of thermal bridges and the probability of failure. The temperature factor can be calculated from the following:

- thermography measurements $f_{\text {Rsi.res }}$ that represent the resistance of the thermal bridge;

- indoor and outdoor climate measurements $f_{\text {Rsi.load }}$ that represent the hygrothermal load effect on the thermal bridge.

Failure (surface condensation or mould growth) occurs if $f_{\text {Rsiload }}>f_{\text {Rsi.res }}$. The resulting probability of failure is the probability of low $f_{\text {Rsi.res }}$ values and high $f_{\text {Rsi.load }}$ values simultaneously (Fig. 2).

The probabilistic approach, presuming the normal distribution of measured temperature factors $f_{\text {Rsi.res }}$ with thermography and critical temperature factors $f_{\text {Rsi.load }}$ based on indoor climate measurements, was used to evaluate the risk of mould growth in the three building types. Critical temperature factors were calculated according to the longterm and large-scale indoor and outdoor climate measurements of Ilomets and Kalamees [24]. The probability of the risk of failure was calculated according to Eq. (2):

$$
\begin{aligned}
& P\left(f_{\text {Rsi.res }}<f_{\text {Rsi.load }}\right) \\
& \quad=\int_{0}^{1} \int_{0}^{f_{\text {Rsires }}} f_{1}\left(f_{\text {Rsi.res }}\right) \cdot f_{2}\left(f_{\text {Rsi.load }}\right) \cdot \mathrm{d} f_{\text {Rsi.res }} \cdot \mathrm{d} f_{\text {Rsi.load }}
\end{aligned}
$$

where: $P$ is probability for the risk of failure; $f_{1}, f_{2}$ are probability density functions of $f_{\text {Rsi.res }}$ and $f_{\text {Rsi.load }}$ respectively; $d$ is differential.

The probability of an event can be easily calculated in MS Excel by inserting Eq. (3):

$$
\begin{aligned}
= & \operatorname{norndist}\left(0, A V G_{\text {fRsi.res }}-A V G_{\text {fRsi.load }}, \operatorname{sqrt}\left(S D_{\text {fRsi.res }}\right.\right. \\
& \left.\left.\cdot S D_{\text {fRsi.res }}+S D_{\text {fRsi.load }} \cdot S D_{\text {fRsi.load }}\right), \text { true }\right)
\end{aligned}
$$

where: normdist refers to normal distribution; $A V G$ is average; sqrt is square root; $S D$ is standard deviation. 
Fig. 2 Cumulative distribution functions from the lowest values of $f_{\text {Rsi.res }}$ from each dwelling unit (based on thermography measurements) and the values of $f_{\text {Rsi.load }}$ from each dwelling unit (based on climate measurements)

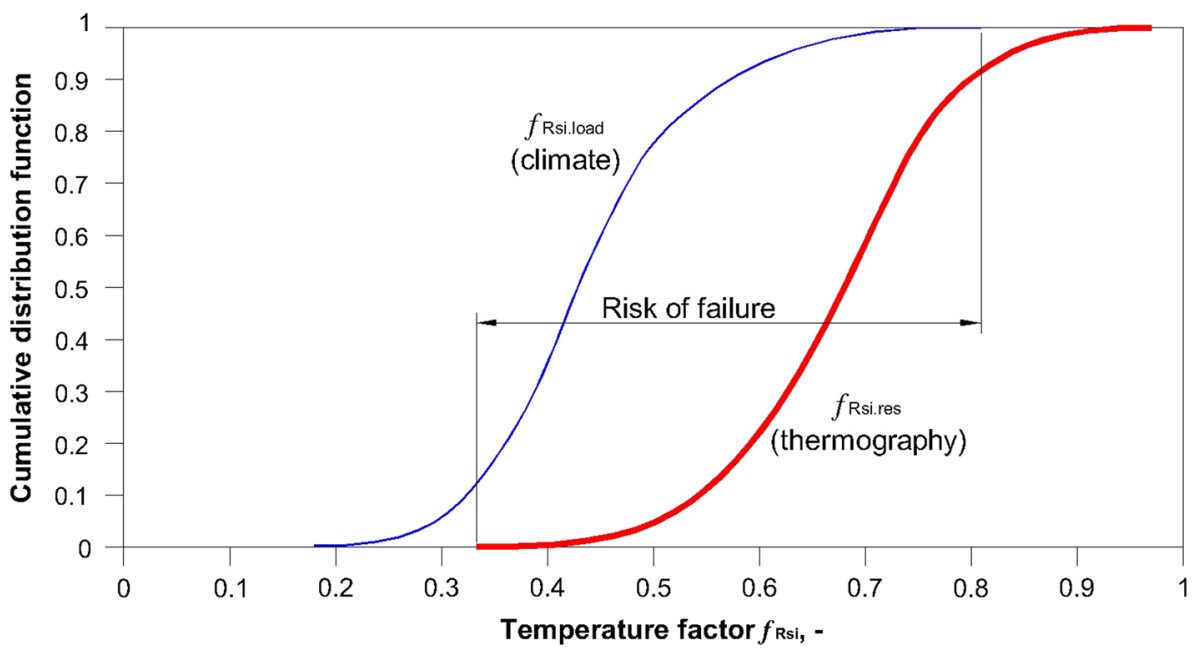

Nutrient availability (substrate), moisture state and temperature are the three most important factors on which mould growth depends [25]. The presence of oxygen is also necessary due to the aerobic nature of mould. It is possible to draw a trend line of mould growth on a building material with various hygrothermal conditions [25]. While surface condensation starts at the RH of $100 \%$, the limit value for $\mathrm{RH}$ in relation to mould growth is from 75 to $95 \%$, depending on temperature variations over time and the group of materials [26-30]. Several mould growth models have been developed, such as the so-called VTT model by Hukka and Viitanen [28], Sedlbauer's isopleths [31], Moon's mould germination method [32] and others. Vereecken and Roels have given a detailed description and studied the impact of the models on the results [33]. As the VTT model has proven to be consistent with the temperature factor approach, it was chosen for the present study. The critical RH for wood, as proposed by Hukka and Viitanen [28], see Eq. 4, may therefore be written as the following:

$$
\begin{aligned}
& R H_{\text {crit }}, \% \\
& =\left\{\begin{array}{lc}
100 & \text { if } t<0^{\circ} C ; \\
-0,00267 \cdot t^{3}+0,160 \cdot t^{2}-3,13 \cdot t+100 & \text { if } 0^{\circ} C \leq t \leq 20^{\circ} C ; \\
80 & \text { if } t>20^{\circ} C ;
\end{array}\right\}
\end{aligned}
$$

where: $t$ is temperature, ${ }^{\circ} \mathrm{C}$.

\section{Results}

A method to evaluate the probability of surface condensation or mould growth on thermal bridges was developed during the course of this study. In the following, the method is described and its application at both building stock and single apartment level is then presented.

\section{Method to evaluate the probability of surface condensation or mould growth on thermal bridges}

The method is based on temperature factor $f_{\mathrm{Rsi}}$, which should be calculated in order to avoid surface condensation and mould growth. The following procedure for calculating critical surface temperature $t_{\text {si.crit }}$ or critical temperature factor $f_{\text {Rsi.crit }}$ is described in EN ISO 13788 [11]. First, the indoor vapour content is calculated from the indoor temperature and $\mathrm{RH}$. Then, with the maximum acceptable $\mathrm{RH}_{\text {crit }}$ (depends on temperature, see Eq. 4) at the thermal bridge surface, the maximum acceptable absolute humidity should be calculated. From that, the minimum acceptable surface temperature, i.e., saturation temperature corresponding to absolute humidity, should be calculated. Using this minimum acceptable surface temperature, outdoor temperature and indoor temperature, the minimum temperature factor should be calculated according to Eq. 1 . As the mould growth depends on time, average monthly climate data could be used. The calculation procedure employed for selecting the critical temperature factor to avoid surface condensation was the same, though the average daily climate values and the maximum acceptable $\mathrm{RH}$ at the thermal envelope's surface $\mathrm{RH}_{\mathrm{si}} 100 \%$ was used. If the variations of all these parameters in Fig. 1 are known, it is possible to make detailed stochastic calculations.

This study was generalised so that only the main sphere of influencing parameters (shaded in Fig. 1) was taken into account:

- $f_{\text {Rsi.res }}=\left(t_{s i}-t_{e}\right) /\left(t_{i}-t_{e}\right)$ is the result of the following parameters:

outdoor air temperature $t_{\mathrm{e}}$ (in macro, meso and micro scale) to be measured during thermography measurements near the studied building;

indoor air temperature $t_{\mathrm{i}}$ to be measured during 
thermography measurements (strongly depends on the performance of the heating systems);

internal surface temperature $t_{\mathrm{si}}$ to be measured by thermography is the result of the following parameters (in addition to indoor and outdoor air temperatures); internal and external surface resistance $R_{\mathrm{si}}, R_{\mathrm{se}}$ (depends on convective and radiative heat transfer coefficients); thermal resistance of a building fabric (depends on the thermal transmittance of the building envelope or thermal bridge, i.e., thermal conductivity $\lambda$ and the thickness $d$ of building materials).

- $f_{R \text { si.load(cond.mould) }}=\left(t_{\text {si.crit(cond.mould })}-t_{e}\right) /\left(t_{i}-t_{e}\right)$ is the result of the following parameters:

time: condensation to be calculated from the daily average (short time, i.e., less frequent than daily, surface condensation is acceptable) and mould growth to be calculated from monthly average (mould germination needs time);

outdoor air temperature $t_{\mathrm{e}}$ (in macro-, meso- and microscale) to be taken from the nearest weather station; indoor air temperature $t_{\mathrm{i}}$ to be measured by data loggers in bedrooms over a 1-year period (strongly depends on the performance and type of heating systems: source and price of energy, the control system and human habits);

critical internal surface temperature $t_{\text {si.crit }}$ to be calculated by using indoor (=internal surface) vapour content and critical $\mathrm{RH}_{\text {crit }}$ (Eq. 4), see the first paragraph of this chapter.

\section{Practical application I: a case study on Estonia's apartment building stock}

\section{Thermography measurements to determine $f_{\text {Rsi.res }}$}

Thermography measurements in buildings showed that the critical thermal bridges are located in the following places (see also Fig. 3):

- the junction of the external wall and windows/doors;

- the junction of the external wall and cellar ceiling;

- the junctions of the external wall (especially end sides) and flat roof;

- the bonds of the inner and outer layers of the external wall elements;

- the external corners of two external walls;

- the junctions of the external wall and the balcony slab (valid for concrete and brick buildings);

- the horizontal and vertical joints between external wall elements (valid for concrete buildings);

- the junction of the external wall and inserted ceiling (mostly for concrete buildings).

In the worst cases, mould growth was visually detected on the internal surface of the thermal bridges, see Fig. 4.

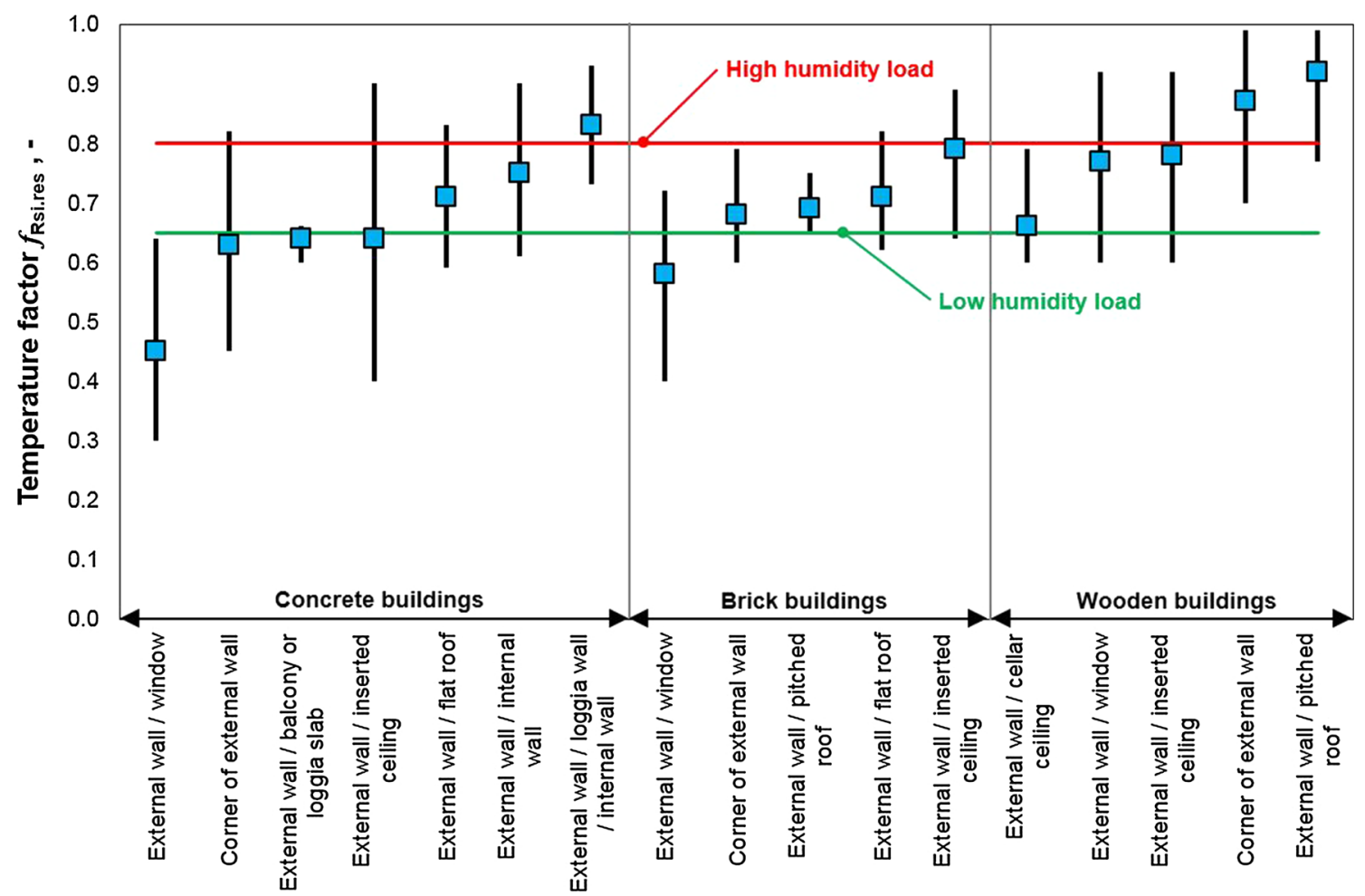

Fig. 3 Measured (by thermography) results of the temperature factors $f_{\text {Rsires }}$ of thermal bridges. The horizontal lines represent the minimum acceptable values for high/low humidity loads in Estonia [16]. The black vertical line shows the range of the results 

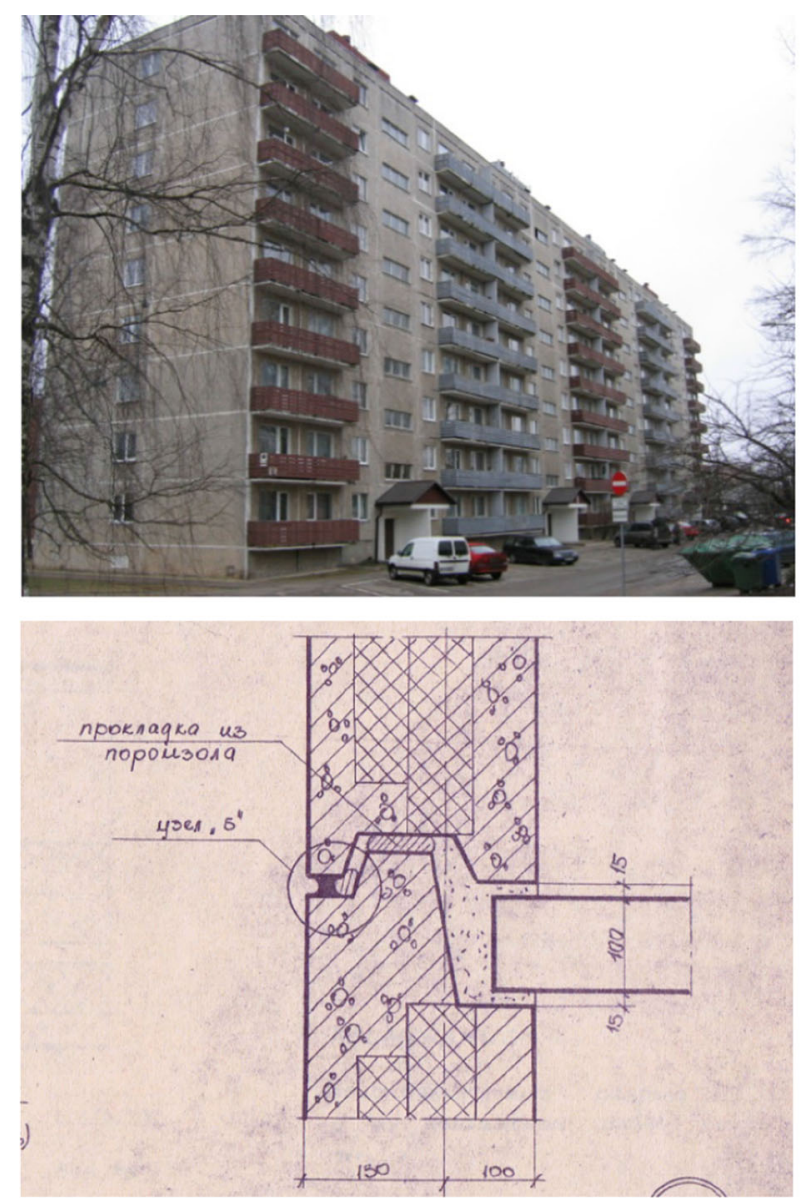

Fig. 4 Example of a precast concrete large-panel apartment building (upper left) with discontinued insulation in the junction of the external wall and floor (lower left). Visible mould growth at the corners of a

\section{Indoor climate measurements to determine $f_{\text {Rsi.load }}$}

Critical temperature factors were calculated based on the indoor and outdoor climate (temperature and $\mathrm{RH}$ ) and the evaluation criterion (surface condensation or mould growth), see Fig. 5. There are significant variations between different dwelling units according to the hygrothermal loads. Each thin curve represents the maximum daily average (for surface condensation) or monthly average (for mould growth) temperature factor $f_{\text {Rsi.load- }}$ cond.mould) at the corresponding outdoor temperature. The maximum temperature factors $f_{\text {Rsi.load }}$ from different dwelling units for surface condensation (left column in Fig. 5) were in the range of $0.21-0.81$ for concrete, $0.38-0.79$ for brick and $0.40-0.83$ for wooden apartment buildings. For mould growth (right column in Fig. 5), temperature factors $f_{\text {Rsi.load }}$ were in the range of $0.18-0.99$ for concrete, $0.26-0.84$ for brick and $0.36-0.95$ for wooden apartment buildings. The temperature factor at $90 \%$ level is around $f_{\text {Rsiload }} \approx 0.7$ but reaches 0.8 for concrete
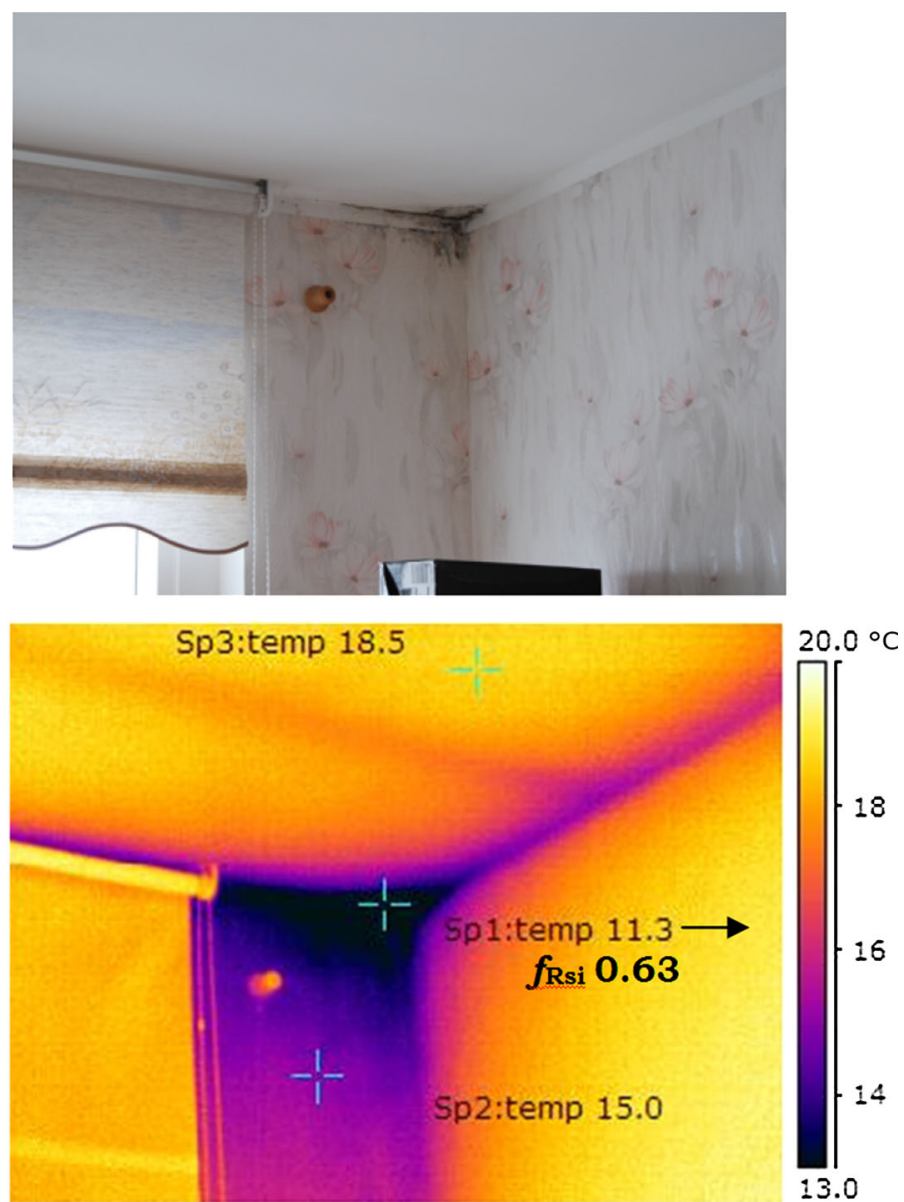

building envelope (upper right) is caused by the thermal bridge (lower right) and high indoor humidity load

buildings with a mould growth criterion. As expected, the load of the condensation criterion is highest during the coldest period in winter, while the risk of mould growth is high up to a daily average outdoor temperature of $10-15{ }^{\circ} \mathrm{C}$.

Probability of failure due to thermal bridges in Estonia's apartment buildings

The presence of mould growth on the internal surfaces of thermal bridges was inspected visually and calculated statistically according to Eq. 3. The probability of mould growth was calculated by comparing the distribution of the lowest temperature factors from each dwelling unit measured with the infrared camera $f_{\text {Rsires }}$ and the highest critical temperature factors calculated from indoor climate measurements $f_{\text {Rsi.load. Figure } 6 \text { presents the results of three }}$ common apartment building types where the temperature factors $f_{\text {Rsi.res }}$ measured with thermography on the horizontal axes should be as near as possible to 1 , with small 


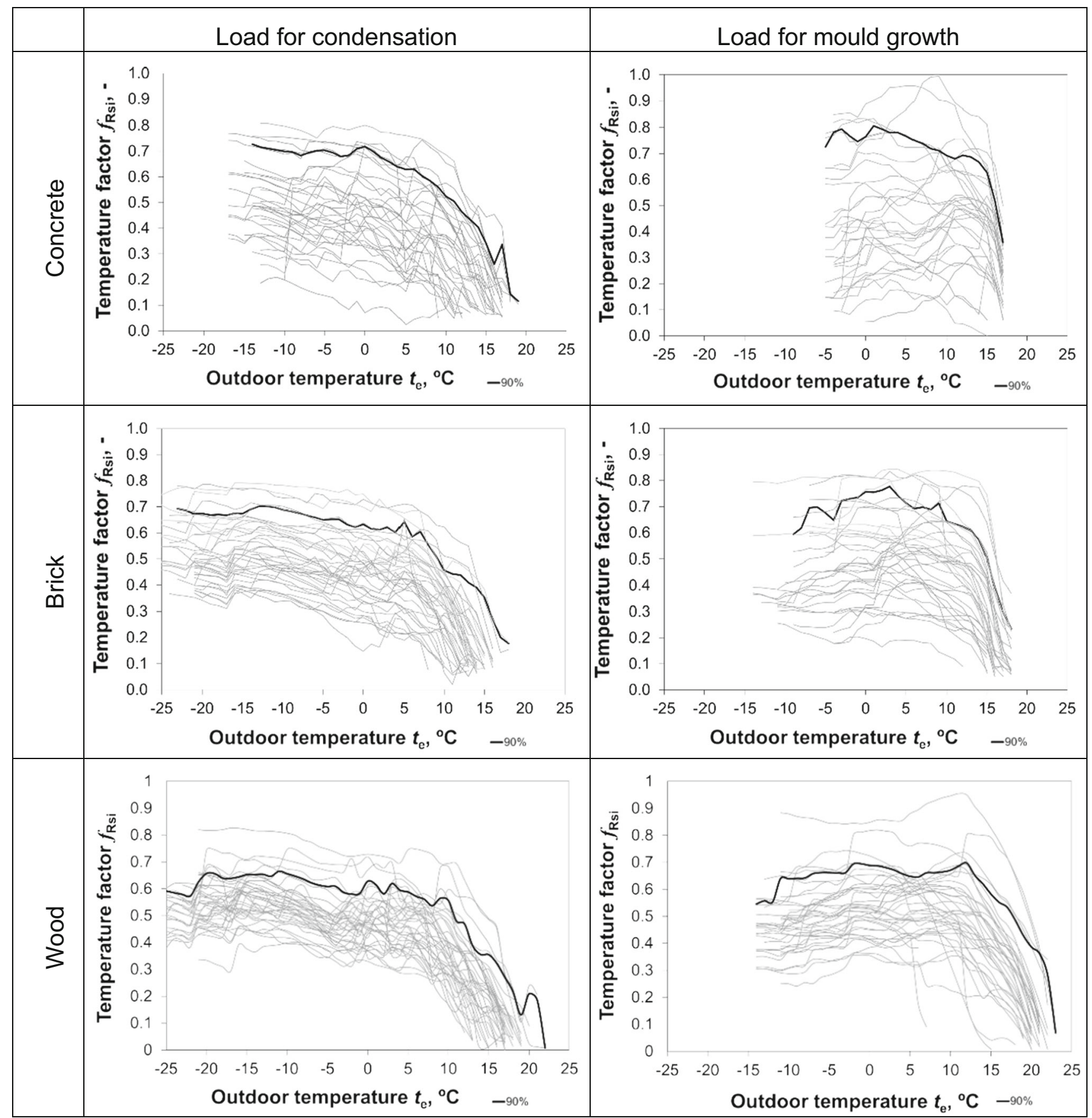

Fig. 5 Temperature factors $f_{\text {Rsi.load(cond.mould) }}$ for surface condensation (left column) and mould growth (right column) in dwelling units (each thin curve) located in concrete apartment buildings (upper row), brick buildings (middle row) and wooden buildings (bottom row)

deviation. Temperature factors $f_{\text {Rsi.load }}$ from climate loads come from Fig. 5 and should be oriented in the middle of the horizontal axes. The presented cumulative distribution curves show that deviation within the temperature factors $f_{\text {Rsi.res }}$ is smallest in the case of brick buildings, where it is expressed as the steepest angle ranging between approximately 0.4 and 0.75 of the line in Fig. 6, middle. There are also no dwelling units with extraordinarily high indoor climate loads over $f_{\text {Rsi.load }}>0.8$ in Fig. 5, middle right. The largest variations of temperature factors $f_{\text {Rsi.res }}$ and $f_{\text {Rsi.load }}$ with the extreme values of $<0.3$ and 1 are in concrete buildings. The high values close to 1 for mould growth $f_{\text {Rsi.load.mould }}$ come from a few dwelling units that have extreme indoor loads (Fig. 5, top right). 


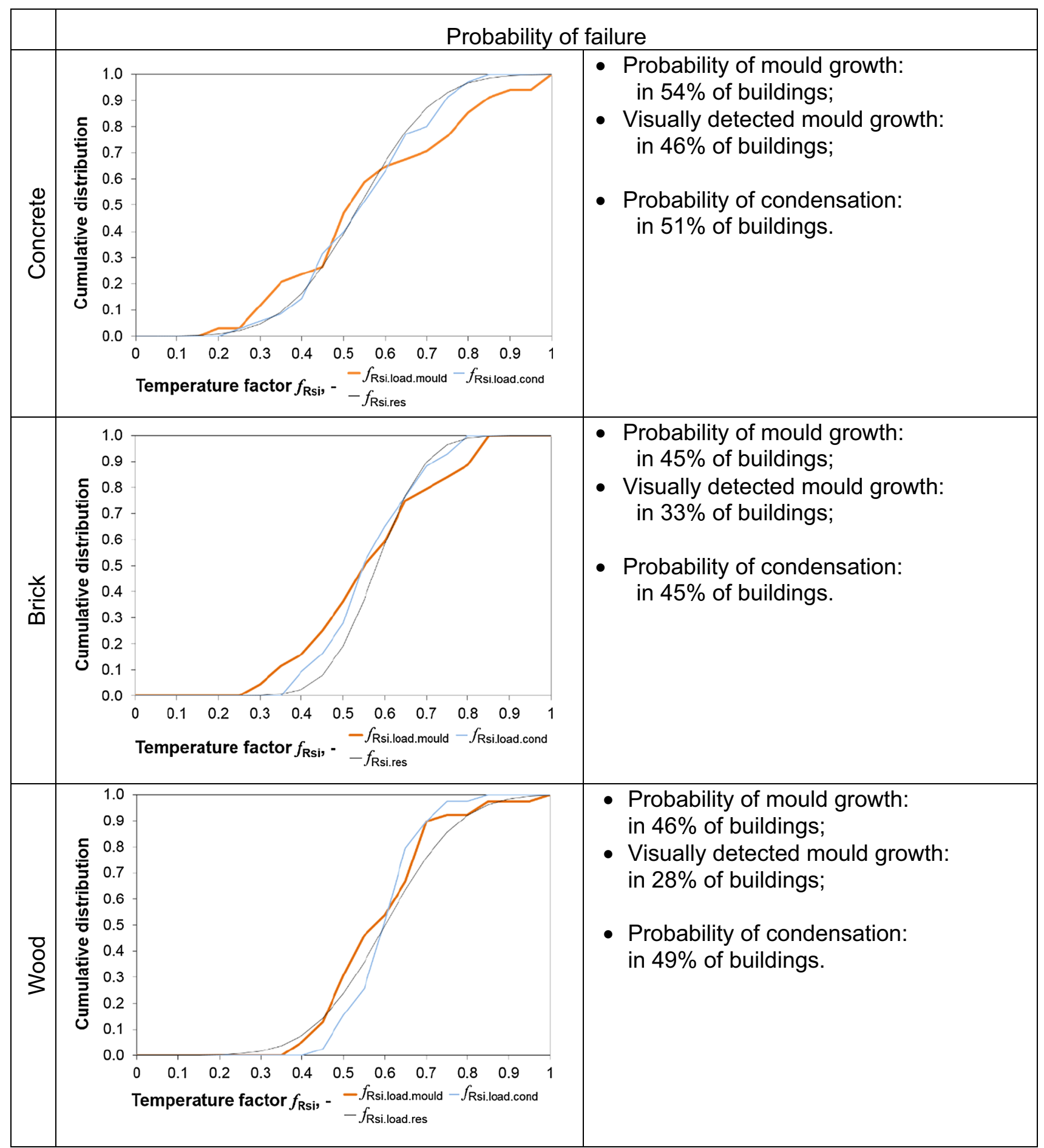

Fig. 6 Distribution of the temperature factors measured with thermography and the temperature factors determined from indoor climate measurements in the studied building types for both failure criteria—surface condensation and mould growth

Since temperature factors $f_{\text {Rsi.res }}$ of $>0.8$ can be considered acceptable, ventilation must be considerably improved in these dwelling units to effect a decrease in the humidity loads. In wooden buildings, one dwelling unit
(Fig. 5, bottom, right) is responsible for a drastic temperature factor $f_{\text {Rsiload.mould }}$ close to 1 . That said, the temperature factor $f_{\text {Rsi.res }}$ is unacceptably low across the board in all building types. 


\section{Practical application II: a case study on a concrete apartment building}

The method to determine the risk of failure due to thermal bridges was also tested on a precast reinforced concrete large-panel apartment building that was renovated due to high energy use and poor indoor climate [34, 35], see Fig. 7. This particular type of construction was common in Estonia and other countries in East and North-East Europe from 1961 to 1990 . About two million $\mathrm{m}^{2}$ of precast concrete large-panel apartment buildings were built in Estonia during that period. The method introduced could also have been applied to a single dwelling unit, but only the presence of risk (or absence thereof) can be evaluated instead of the numerical value for the risk of failure.

\section{Thermography measurements to determine $f_{R s i . r e s}$}

In our case study, the thermography measurements in six dwelling units (including ground and top storeys) showed that the critical thermal bridges before the renovation are located in:
- horizontal and vertical joints between external wall elements: $f_{\text {Rsi.res }} 0.68-0.80$;

- the outer corner of external walls: $f_{\text {Rsi.res }} 0.60-0.73$;

- the junction of the external wall and the balcony slab;

- the junction of the external wall (especially end sides) and flat roof (3D corner): $f_{\text {Rsi.res }} 0.61-0.65$;

- bonds of the inner and outer layers of the external wall elements;

- the external wall/foundation wall elements (3D corner): $f_{\text {Rsi.res }} 0.43-0.62$;

- the junction of the external wall and the window/door (3D corner): $f_{\text {Rsi.res }} 0.66-0.70$.

As an example, the improvement after installing ETICS in the course of the renovation increased the temperature factor of the window/wall sample junction from $f_{\text {Rsi.res }}=0.68$ to $f_{\text {Rsi.res }}=0.84$, see Fig. 8 .

\section{Indoor climate measurements to determine $f_{\text {Rsiload }}$}

Available information about the present situation of $f_{\text {Rsi.load }}$ was collected by measuring the indoor air temperature and
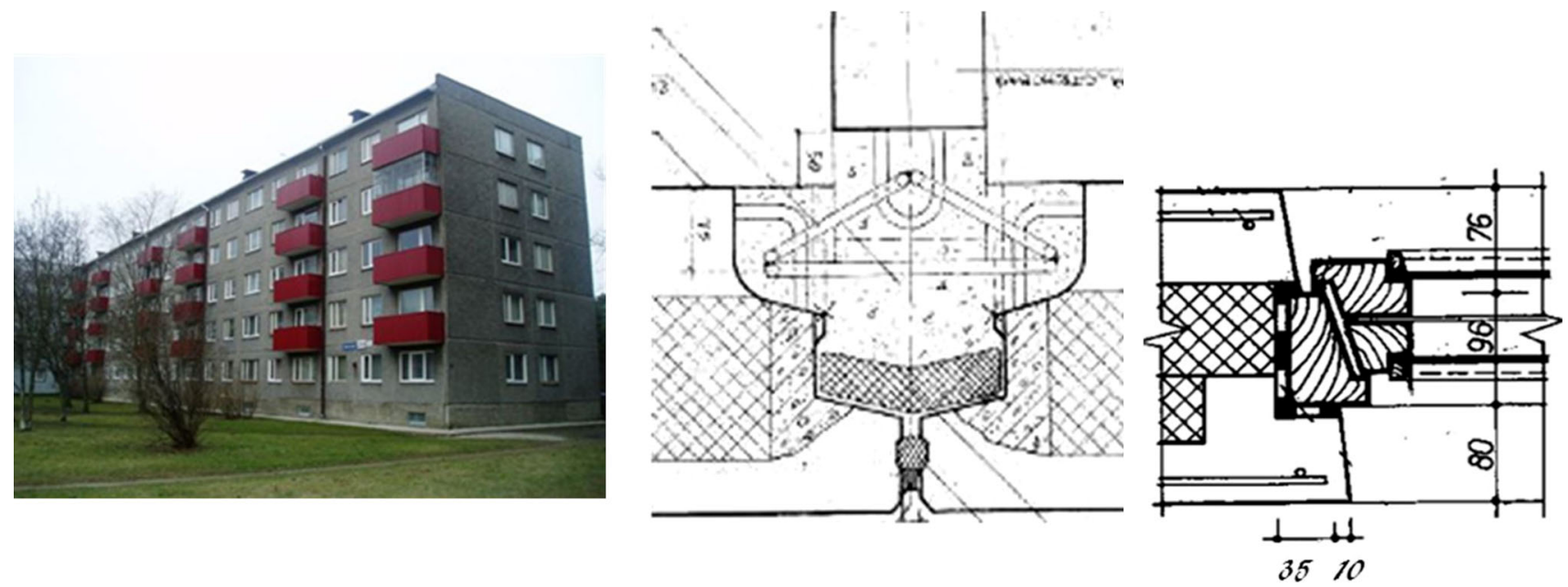

Fig. 7 The studied concrete large-panel apartment building before renovation (left) and its original design drawings-junction of external wall/ internal wall (middle) and junction of external wall/window (right)
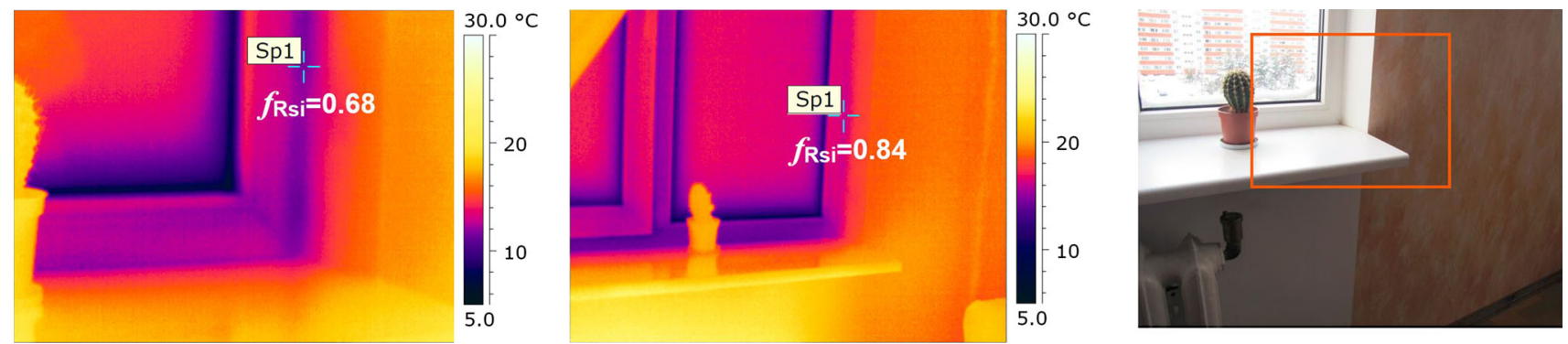

Fig. 8 Measured (by thermography) results of the temperature factors $f_{\text {Rsi res }}$ of thermal bridges before (left) and after the renovation (middle) of the external wall/window junction (illustrating picture of a junction in the right). The window was not replaced during the renovation 

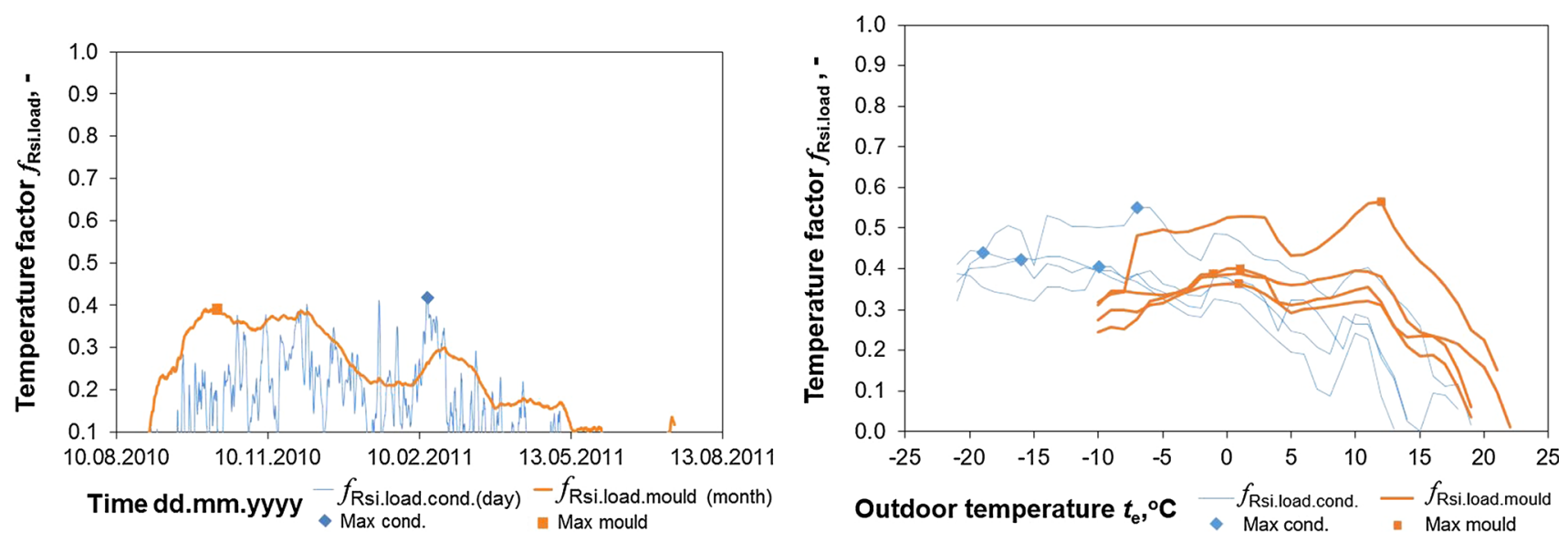

Fig. 9 Critical temperature factors $f_{\text {Rsi.load(cond.mould) }}$ of one dwelling unit during a 1-year period (left) and the same for four dwelling units arranged according to outdoor air temperature before the renovation (right)

RH over the course of a year prior to the renovation. Measurements and thermography were taken in the same dwelling units.

Critical temperature factors were calculated based on the indoor and outdoor climate (temperature and $\mathrm{RH}$ ) data and the assessment criterion (surface condensation or mould growth), (Fig. 9, based on example of Fig. 5). The critical temperature factor for surface condensation $f_{\text {Rsi.load(cond.) }}$ is highest during the winter; see Fig. 9, left. In terms of mould growth, $f_{\text {Rsi.load(mould) }}$ becomes significant during the autumn. The risk of mould growth is relatively low in spring, although the outdoor temperature is similar to that in autumn; however, the RH of outdoor air is much lower in spring. Each curve in Fig. 9, right, represents the maximum daily average (for surface condensation) or monthly average (for mould growth) temperature factor $f_{\mathrm{Rsi} \text {,load(cond.mould) }}$ at the corresponding outdoor temperature. One dwelling unit on an upper storey has higher indoor hygrothermal loads in comparison to the other three units. The maximum temperature factors $f_{\text {Rsi.load }}$ from different dwelling units before the renovation varied between 0.40 and 0.55 for surface condensation and $0.36-0.57$ for mould growth. Compared to concrete buildings in a whole building stock level, our case study building had quite average indoor hygrothermal loads prior to renovation. Although the heating and ventilation systems were upgraded during the renovation, the indoor climate is assumed to remain the same in order to analyse the improved performance of the building envelope.

\section{Probability of failure due to thermal bridges in a case study building}

The probability of surface condensation and mould growth was calculated according to Eq. (3), by comparing

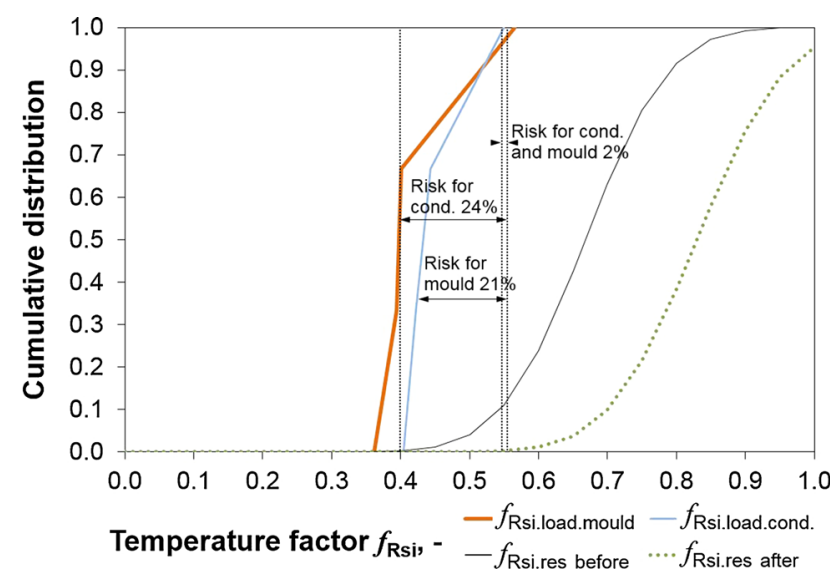

Fig. 10 Distribution of the temperature factors $f_{\text {Rsi,load }}$ and temperature factors measured with thermography $f_{\text {Rsi,res }}$, before and after the renovation. The temperature factor $f_{\text {Rsiload }}$ from the indoor climate before and after renovation remained unchanged

the distribution of the temperature factors measured with the infrared camera $f_{\text {Rsi.res }}$ and the critical temperature factors calculated from the indoor climate measurements $f_{\text {Rsi.load. }}$ Figure 10 presents the probability of surface condensation before the renovation as $24 \%$ and of mould growth as $21 \%$. The risk of both is unacceptably high and the energy renovation of the building must cover the thermal bridges.

We were also able to measure the temperatures factors $f_{\text {Rsi.res }}$ after the renovation. The probability of surface condensation and mould growth after renovation resulted in $2 \%$ for both criteria, as presented graphically in Fig. 10. A target of $0 \%$ for the risk level was chosen, which was assumed to be reached with all the temperature factors $f_{\text {Rsi.res }}$ at $>0.8$. This target was not achieved since some of the measured temperature factors were lower than those calculated. 


\section{Discussion}

The method proposed in this study and its application to evaluate the criticality of thermal bridges can be advised. The calculated risk for mould growth does not differ much from the percentage actually detected in dwelling units by visual observations and later confirmed to be mould in the laboratory. The advantage of the method is its ability to avoid uncertainties emanating from 2D vs 3D junctions, since the actual long-wave radiation emitted from the surface (i.e., surface temperature) is measured. When calculating the impact on thermal bridges due to renovation, the 3D approach should be performed. A sufficient quantity (48 dwelling units were used in this study) of the measured indoor surface temperatures and indoor loads should be analysed in order to decrease this uncertainty. The distribution function of the data should always be examined.

As Figs. 3 and 6 shows, the lowest temperature factors $f_{\text {Rsi.res }}$ measured by thermography exist in concrete apartment buildings. The calculated probability for the surface condensation exceeded $50 \%$ for concrete and was close to $50 \%$ for wooden and brick buildings. The calculated probability (and also visually detected) of mould growth is also the highest for concrete buildings; though it is somewhat lower for wooden and brick buildings, it is still at an unacceptably high level. Most frequently, mould growth was found on the 3D corners of different junctions of the external wall. The criterion for mould growth $\mathrm{RH}_{\text {crit }}=80 \%$ (Eq. 4) was developed by Hukka and Viitanen [28] using wooden samples. The model was updated by Ojanen et al. [30] who proposed $\mathrm{RH}_{\text {crit }}=80 \%$ as a proper value for building materials that are "sensitive" to mould growth. Wooden based wallpaper and boards covered with paper were often used for the interior finishing in bedrooms, living rooms and kitchens of dwellings in the present study. These materials belong to the "sensitive" class and detected mould growth is consistent with the classes proposed by Ojanen. Furthermore, to eliminate problems caused by thermal bridges, additional thermal insulation of $150 \mathrm{~mm}$ is sufficient, as shown in Ilomets and Kalamees [35]. In light of more strict energy efficiency requirements today and in the future, thicker insulation, e.g., $\geq 200 \mathrm{~mm}$ for external walls, is advised. This would notably increase the building envelope's internal surface temperature and improve indoor thermal comfort.

The results of temperature factors $f_{\text {Rsi.res }}$ in Fig. 3, measured by infrared thermography, refer to extremely low levels and significant variations within each junction, especially in terms of window junctions. The significant variations within the results indicate deficiencies in the quality of workmanship and variations in structural junctions due to different building types and series.
The present measurements prove the results of the previous study by Kalamees [16]: to avoid mould growth and surface condensation in dwellings with high indoor humidity loads [24], the temperature factor should be $f_{\mathrm{Rsi}}>0.8$ at $10 \%$ critical level. The lines at higher temperature factors (Fig. 5) correlate with the higher moisture excess $\Delta v, \mathrm{~g} / \mathrm{m}^{3}$ calculated from indoor and outdoor climate measurements. Also, the findings are largely consistent with $f_{\mathrm{Rsi}}>0.7$ at $5 \%$ critical level [33], especially for wooden buildings.

The proposed method is a useful tool for evaluating the renovation need of the building envelope of old apartment buildings that are characterised with high indoor humidity loads and/or low temperature factors $f_{\mathrm{Rsi}}$. Measuring indoor air temperature and $\mathrm{RH}$ as well as internal surface temperature by using thermography could be utilised as a regular, non-destructive, relatively simple and inexpensive process in the assessment of the technical condition of a single dwelling unit, a building, a district, or a whole housing stock. The impact of upgrading the building envelope or lowering humidity loads via improving ventilation can be analysed during the renovation design.

Overall, a building's low energy performance in the twentieth century, a historical lack of high quality building materials and workmanship, and poor records of operation and maintenance are the main reasons why the majority of older housing stock fail to meet today's standards. The largest shortcomings are related to indoor climate and energy performance as well as natural degradation mechanism, e.g., carbonation induced corrosion and frost damage [36]. As this study proves, the poor hygrothermal performance of a building envelope is also characterised by critical thermal bridges. Therefore, a situation has been reached whereby a huge number of buildings are in need of inevitable renovation.

\section{Conclusions}

The study had two aims-first, to propose a method and, second, to evaluate the criticality of thermal bridges by using the proposed method based on the temperature factor $f_{\mathrm{Rsi}}$. The risk of surface condensation and mould growth was calculated from the measured results of $f_{\text {Rsi.res }}$ by using thermography and from measured indoor hygrothermal loads expressed as $f_{\text {Rsi.load }}$.

The results show that critical thermal bridges caused by a low surface temperature exist in all types of apartment buildings. The measured temperature factors were as low as $f_{\text {Rsi.res }}<0.65$ on average for several junctions of concrete buildings and for the external wall/window junctions of brick buildings. The temperature factors from indoor hygrothermal loads were as high as $f_{\text {Rsi.load }}=0.99$ for the 
worst dwelling unit and $f_{\text {Rsi.load }}=0.80$ at $90 \%$ reliability level for mould growth in concrete buildings. The calculated risk for surface condensation is $51 \%$ for concrete buildings and close to $50 \%$ for wooden and brick buildings. The probability of mould growth in concrete buildings is $54 \%$, in wooden buildings $46 \%$ and in brick buildings $45 \%$. The calculated results are confirmed by detected mould growth ranging between 28 and $46 \%$ in the studied dwelling units.

One of the main reasons for renovating old apartment buildings in Estonia is to eliminate critical thermal bridges that cause mould growth. Furthermore, additional external thermal insulation reduces heat loss, leads to a higher internal surface temperature that improves thermal comfort and protects the building façade against outdoor climate loads.

Acknowledgements This research was supported by the Estonian Centre of Excellence in Zero Energy and Resource Efficient Smart Buildings and Districts, ZEBE, grant TK146 funded by the European Regional Development Fund, and by the Estonian Research Council, with Institutional research funding grant IUT1-15.

\section{References}

1. Birkeland O (1979) Energy losses through thermal bridges. Batim Int Build Res Pract 7:284. doi:10.1080/09613217908550792

2. Andersson AC (1980) Insulation and the thermal bridge effect. Batim Int Build Res Pract 8:222. doi:10.1080/ 09613218008550868

3. Fang JB, Grot RA, Childs KW, Courville GE (2008) Heat loss from thermal bridges. Batim Int Build Res Pract 12:346-352. doi:10.1080/09613218408545298

4. Varga T, Ingeli R (2016) The effect of thermal bridges on energy balance of wood frame houses. Appl Mech Mater 824:323-330. doi:10.4028/www.scientific.net/AMM.824.323

5. Mend'an R, Pavčeková M (2016) The influence of thermal bridges on the energy need for heating after renewal: a case study. Appl Mech Mater 824:307-314. doi:10.4028/www.scientific.net/ AMM.824.307

6. Ge H, Baba F (2015) Dynamic effect of thermal bridges on the energy performance of a low-rise residential building. Energy Build 105:106-118. doi:10.1016/j.enbuild.2015.07.023

7. Berggren B, Wall M (2013) Calculation of thermal bridges in (Nordic) building envelopes-risk of performance failure due to inconsistent use of methodology. Energy Build 65:331-339. doi:10.1016/j.enbuild.2013.06.021

8. Altan H, Kim YK (2014) Non Repeating Thermal Bridges and the Impact on Overall Heating Energy Consumption in a Typical UK Home. In: Dincer I, Midilli A, Kucuk H (eds) Progess in sustainable energy technologies, vol II. Springer International Publishing, Cham, pp 109-122. doi:10.1007/978-3-319-07977-6

9. Janssens A, Van Londersele E, Vandermarcke B, Roels S, Standaert P, Wouters P (2007) Development of limits for the linear thermal transmittance of thermal bridges in buildings. Therm. Perform. Exter. Envel. Whole Build. X Int. Conf., Clearwater, Florida

10. IEA Annex 14 (1990) Condensation and energy, guidelines and practice. In: Hens $\mathrm{H}$ (ed) Laboratory for building physics, Belgium, KU Leuven, p 55
11. EN ISO 13788 (2012) Hygrothermal performance of building components and building elements-internal surface temperature to avoid critical surface humidity and interstitial condensationcalculation methods

12. ISO 10211 (2007) Thermal bridges in building constructionheat flows and surface temperatures-detailed calculations

13. ISO 6781-3 (2015) Performance of buildings - detection of heat, air and moisture irregularities in buildings by infrared methodsPart 3: qualifications of equipment operators, data analysts and report writers

14. EN 13187 (2001) Thermal performance of buildings-qualitative detection of thermal irregularities in building envelopes-infrared method

15. STM 545 (2015) Sosiaali- ja terveysministeriön asetus asunnon ja muun oleskelutilan terveydellisistä olosuhteista sekä ulkopuolisten asiantuntijoiden pätevyysvaatimuksista. Helsinki

16. Kalamees $\mathrm{T}$ (2006) Critical values for the temperature factor to assess thermal bridges. Proc Est Acad Sci Eng 12:218-229

17. DIN 4108-2 (2013) Wärmeschutz und Energie-Einsparung in Gebäuden-Teil 2: Mindestanforderungen an den Wärmeschutz

18. SIA-180 (1999) Wärme- und Feuchteschutz im Hochbau. Schweizerische Ingenieur- und Architektenverein. Zürich

19. Ward TJ (2006) Assessing the effects of thermal bridging at junctions and around openings. BRE information paper IP 1/06. BRE Press, Garston, Glasgow, Scotland. https://www.brebook shop.com/details.jsp?id=190162

20. Wouters P, Schietecat J, Standaert P (2003) Practical guide for the hygrothermal evaluation of thermal bridges. Project document. Eurokobra

21. Ilomets S, Kuusk K, Paap L, Arumägi E, Kalamees T (2016) Impact of linear thermal bridges on thermal transmittance of renovated apartment buildings. J Civ Eng Manag. doi:10.3846/ 13923730.2014 .976259

22. Mend'an R, Vavrovič B (2013) Renewal of envelope constructions of panel residential houses as a tool for elimination of hygienic problems of thermal bridges. Adv Mater Res 855:89-92. doi:10.4028/www.scientific.net/AMR.855.89

23. Harris JL (2000) Safe, low-distortion tape touch method for fungal slide mounts. J Clin Microbiol 38:4683-4684

24. Ilomets S, Kalamees T (2016) Indoor hygrothermal loads for the deterministic and stochastic design of the building envelope of dwellings in cold climates. J Build Phys (in process after minor revision)

25. Li Y (2014) System model of mould growth on building materials. XIII Conf. Durab. Build. Mater. Components, pp 231-5

26. Johansson P, Ekstrand-Tobin A, Svensson T, Bok G (2012) Laboratory study to determine the critical moisture level for mould growth on building materials. Int Biodeterior Biodegradation 73:23-32. doi:10.1016/j.ibiod.2012.05.014

27. Johansson P, Ekstrand-Tobin A, Bok G (2014) An innovative test method for evaluating the critical moisture level for mould growth on building materials. Build Environ 81:404-409. doi:10. 1016/j.buildenv.2014.07.002

28. Hukka A, Viitanen H (1999) A mathematical model of mould growth on wooden material. Wood Sci Technol 33:475-485. doi:10.1007/s002260050131

29. IEA EBC Annex 41 (2008) Whole building heat, air and moisture response (MOIST-EN)

30. Ojanen T, Viitanen H, Peuhkuri R, Vinha J, Salminen K (2010) Mold growth modeling of building structures using sensitivity classes of materials. XI Int. Conf. Perform. Exter. Envel. Whole Build

31. Sedlbauer K (2002) Prediction of mould growth by hygrothermal calculation. J Build Phys 25:321-336. doi:10.1177/ 0075424202025004093 
32. Moon HJ (2005) Assessing mold risk in buildings uncertainty. Georgia Institute of Technology

33. Vereecken E, Roels S (2014) Mould risk assessment for thermal bridges: what is the impact of the mould prediction model? XIII Conf. Durab. Build. Mater. Components, pp 599-606

34. Kuusk K, Kalamees T, Link S, Ilomets S, Mikola A (2016) Casestudy analysis of concrete large-panel apartment building at preand post low-budget energy renovation. J Civ Eng Manag. pp 1-9. doi:10.3846/13923730.2014.975741
35. Ilomets S, Kalamees $\mathrm{T}$ (2013) Case-study analysis on hygrothermal performance of ETICS on concrete wall after lowbudget energy-renovation. Proc. XII Int. Conf. Perform. Exter. Envel. Whole Build. Florida, USA, December 1-5, 2013, ASHRAE

36. Ilomets S, Kalamees T, Agasild T, Õiger K, Raado L (2011) Durability of concrete and brick facades of apartment buildings built between 1960-90 in Estonia. 12th Int. Conf. Durab. Build. Mater. Components, vol. III, Porto, pp 1171-8 